\title{
Chromosomal polymorphisms associated with reproductive outcomes after IVF-ET
}

\author{
Sai-jiao $\mathrm{Li}^{1,2} \cdot$ Yan-xiang Cheng ${ }^{3} \cdot$ Ye-Shang ${ }^{1,2} \cdot$ Dan-ni Zhou ${ }^{1,2} \cdot$ Yin Zhang ${ }^{1,2} \cdot$ Tai-lang Yin $^{1,2} \cdot$ Jing Yang ${ }^{1,2}$
}

Received: 18 December 2019 / Accepted: 22 April 2020 / Published online: 25 May 2020

(C) The Author(s) 2020

\begin{abstract}
Purpose This study aimed to investigate the effect of the detail type of chromosomal polymorphisms $\left(1 / 9 / 16 \mathrm{qh}^{+/}\right.$, D/G group polymorphisms, and inv(9)) on the IVF-ET outcomes.

Methods A total of 1335 infertile couples undergoing IVF/ICSI were enrolled and comprehensively analyzed the correlation between three detail types of chromosomal polymorphisms $\left(1 / 9 / 16 \mathrm{qh}^{+/-}, \mathrm{D} / \mathrm{G}\right.$ group polymorphisms, and inv(9)) and the outcome of IVF/ICSI embryo transfer. The fertilized rate, cleaved embryo rate, good-quality embryo rate, clinical pregnancy rate, implantation rate, and early stage miscarriage rate were compared between the chromosomal polymorphisms groups and the control group.

Results Both the inv(9) and D/G group chromosomal polymorphisms related to female infertility significantly lead to a lower 2PN cleavage rate $(86.44 \%$ vs. $97.58 \%$ and $90.67 \%$ vs. $97.58 \%$, respectively, $P<0.05)$ undergoing IVF insemination, the inv(9) adversely increasing the early miscarriage rate, either undergoing IVF $(21.4 \%$ vs. $3.0 \%, P<0.05)$ or ICSI $(50.0 \%$ vs. $2.0 \%$, $P<0.05)$ insemination, female carriers $(23.08 \%$ vs. $2.87 \%, P<0.05)$ or male carriers $(44.44 \%$ vs. $2.87 \%, P<0.05)$. For D/G groups, ICSI insemination may increase the implantation rate $(44.8 \%$ vs. $23.69 \%, P<0.05)$ and clinical pregnancy rate $(78.6 \%$ vs. $40.65 \%, P<0.05) .1 / 9 / 16 \mathrm{qh}^{+/-}$had no apparent adverse effect on the patient's clinical outcomes.

Conclusions Our study suggests that chromosome karyotype analysis is necessary for IVF patients in clinical practice; we should afford individual genetic counseling suggestion according to the polymorphism types.
\end{abstract}

Keywords Chromosomal polymorphism $\cdot$ IVF-ET $\cdot$ inv(9) $\cdot$ Miscarriage

\section{Introduction}

Chromosomal polymorphisms mainly refer to variants in the chromosomal heterochromatin region. In routine cytogenetics, increases or decreases in the lengths of the heterochromatic regions on the long arms of these

Sai-jiao Li and Yan-xiang Cheng contributed equally to this work.

Jing Yang

dryangqing@hotmail.com

1 Reproductive Medical Center, Renmin Hospital of Wuhan University, No. 238 JieFang Road, Wuhan 430060, People's Republic of China

2 Hubei Clinic Research Center for Assisted Reproductive Technology and Embryonic Development, No. 238 JieFang Road,

Wuhan 430060, People's Republic of China

3 Gynecology Department, Renmin Hospital of Wuhan University, No. 238 JieFang Road, Wuhan 430060, People's Republic of China chromosomes are designated as $1 \mathrm{qh}^{+/-}, 9 \mathrm{qh}^{+/-}, 16 \mathrm{qh}^{+/-}$, and $\mathrm{Yqh}^{+/-}$. Findings regarding these regions are prevalent, and the frequencies of $9 \mathrm{qh}^{+}$and $\mathrm{Yqh}^{+}$have been reported to be approximately $2.44 \%$ and $2.85 \%$, respectively [1]. However, more earlier reports presented a higher incidence of approximately $7.60 \%$ for $9 \mathrm{qh}^{+}$polymorphisms $[2,3]$. An increase or decrease in the length of the short arm of acrocentric (acro) D-genome and G-genome $(D / G)$ group chromosomes is designated $\mathrm{p} \pm$, while an increase or decrease in the length of short arm satellites and stalks is designated $\mathrm{ps}^{+/-}$and $\mathrm{pstk}^{+/-}$, respectively $[4,5]$. Variants in the $\mathrm{D} / \mathrm{G}$ group have been reported to constitute approximately $3.96 \%$ of variants (1). Pericentric inversion of chromosome 9-regularly referred to as inversion 9 (inv(9)) - is one of the most common variations in the human karyotype; the estimated frequency varies from 1 to $4 \%$ in extensive epidemiological studies [6-11]. The latest version of the International System for Cytogenetic Nomenclature (ISCN) [12] refers to inv(9) (p12q13) as a 
chromosomal polymorphism (or generally heteromorphism) with no clinical significance.

For a long time, constitutive heterochromatin has been categorized as minor chromosomal rearrangements, which are formed by tandemly organized, highly repeated sequences of satellite DNA that have no apparent coding potential and do not correlate with abnormal phenotypes $[13,14]$. However, an increasing number of studies have reported the potential effects of chromosomal polymorphisms on reproductive capacity.

In recent years, a growing number of studies have reported an increased incidence of chromosomal polymorphism variations in infertile couples [15-18], in patients with spontaneous miscarriages [19-22] and even in patients with psychiatric disorders [23]. However, how chromosomal polymorphisms affect fertility remains unclear. Very few reports had concern the impact of chromosomal polymorphic variations on assisted reproductive technology (ART) outcomes [24-27]. Besides, most of the studies just focus on the ART treatment outcomes of infertile males with $\mathrm{Y}$ chromosomal variations [25-28]; only a few studies had especially paid attention to the ART outcomes of the female with chromosomal polymorphisms. Moreover, the majority of the previous reports simply combined all chromosomal heteromorphism types into one group to study their effects on fertility [29, 30]. No study, however, has stratified infertility according to the specific type of chromosomal polymorphism, other than $\mathrm{Y}$ chromosome variations, on infertility treatments, including IVF-embryo transfer.

Therefore, this retrospective study comprehensively analyzed the correlations between chromosomal polymorphisms, which were subdivided into three groups (the $1 / 9 / 16 \mathrm{qh}^{+/-}$ group, D/G group, and inv(9) group), and the outcome of IVF-embryo transfer in infertile couples.

\section{Materials and methods}

\section{Participants}

A retrospective, single-center cohort study was conducted between October 2014 and November 2017 at the Reproductive Medicine Center in Renmin Hospital of Wuhan University in Wuhan, China. Infertile couples who had received their first IVF-embryo transfer treatment cycle and carried out karyotype analyses were included.

\section{Chromosome karyotype analysis}

G-banded chromosome karyotype analysis of cultured peripheral blood lymphocytes was carried out for all ART couples. At least 20 metaphases were analyzed, and five metaphases were karyotyped for each case. The banding resolution was
400-550 bands per haploid set (BPHS). Two independent researchers confirmed all slides, and the results were reported according to the ISCN 2009 after selective banding studies. Cbanding and nucleolar organizing region (NOR) banding were conducted to assist the karyotype analysis. Distinct polymorphic variants of the lengths of the stalks (pstk) and the size of the satellites (ps) of the acro chromosomes were documented, and the variant was at least twice the size of its corresponding region on the other homolog. Polymorphic variations in centromeric heterochromatin length on the long arms of chromosomes 1, 9, and 16 (1qh, 9qh, and 16qh) were also recorded. Only consistent and very prominent polymorphisms were reported; additionally, it was noted that these were normal variants.

\section{Study design}

Infertile couples were divided into four groups according to the karyotype analysis results: 129 couples with $1 \mathrm{qh}^{+/}, 9 \mathrm{qh}^{+-}$, or $16 \mathrm{qh}^{+/-}\left(1 / 9 / 16 \mathrm{qh}^{+-}\right.$group); 55 couples with $\mathrm{ps}^{+/-}$, pss, or $\mathrm{pstk}^{+/-}$of the variants in the NOR of the acro chromosomes (D/G group); 62 couples with pericentric inversion of chromosomes 9 (inv(9) group) and 1088 couples with normal chromosomes (control group) in which the etiology of infertility was the female tubal factor. The frequency of chromosomal polymorphic variations was calculated. The exclusion criteria were as follows: the female reproductive age $\geq 38$ years, body mass index $(\mathrm{BMI})<18$ or $>25 \mathrm{~kg} / \mathrm{m}^{2}$, day 3 FSH concentration $>$ $10 \mathrm{IU} / \mathrm{L}$, ovulation dysfunction (such as polycystic ovarian syndrome) or female with endocrine disorders (diabetes mellitus, thyroid dysfunction, hyperprolactinemia, congenital adrenal hyperplasia, Cushing syndrome), or uterine anomaly confirmed by either hysterosalpingography or hysteroscopy. Couples with polymorphic variants of chromosomes in both males and females were excluded from the study.

\section{In vitro fertilization/intracytoplasmic sperm injection procedure}

The patients underwent ovarian stimulation accomplished with a $\mathrm{GnRH}$ antagonist protocol or long luteal downregulation protocol. All patients had a baseline transvaginal ultrasound on menstrual cycle day 2 or day 3. Patient response was monitored with transvaginal ultrasounds for follicular measurements and serum estradiol $\left(\mathrm{E}_{2}\right)$ levels. When three follicles diameter reached $\geq 17 \mathrm{~mm}$, patients were triggered with 10,000 IU HCG intramuscularly. Oocyte retrieval was performed $36 \mathrm{~h}$ later. Intracytoplasmic sperm injection (ICSI) was performed if the concentration of motile sperm was < $1 \times 10^{6} / \mathrm{mL}$ after sperm preparation on the day of oocyte retrieval; otherwise, a conventional IVF method was used. Embryo transfers were performed $72 \mathrm{~h}$ after oocyte retrieval. 
Monitoring of patients included general information, symptoms, embryonic condition, BMI, and other independent variables consisted of female age, IVF or ICSI, female basal FSH, the protocol of ovarian stimulation, the dosage of gonadotrophin $(\mathrm{Gn})$, the sex hormone level on the day of HCG injected, the thickness of endometrium on HCG day, and the oocytes retrieved number. The fertilized rate, 2 pronuclei (2PN) cleaved rate, good-quality embryo rate, clinical pregnancy rate (CPR, gestational sac seen at 6.5 weeks), implantation rate (number of gestational sacs seen at 6.5 weeks per number of embryos transferred), and early stage miscarriage rate were calculated and compared between the four groups.

\section{Statistical analysis}

All statistical analyses were performed with the SPSS 24.0 statistical software (Chicago, IL, USA) according to the intention to treat principle. Data were presented as mean $\pm \mathrm{SD}$. Chisquare or Fisher exact tests were used for categorical $l$ variables. ANOVA were performed on comparison among multiple groups. A significant result means that the $P$ value for the ordinal level measure is $<0.05$, and the confidence interval (CI) is $95 \%$.

\section{Results}

As shown in Table 1, 246 out of 1335 couples carried chromosomal polymorphisms: the male carriers accounted for $53.25 \%$ (131/246), and female carriers accounted for $46.75 \%$ (115/246). In males, the $\mathrm{Yqh}^{+/-}$polymorphisms were not present, the most frequent polymorphism type was $1 \mathrm{qh}^{+-}(32.06 \%)$, and the least frequent polymorphism type was $15 \mathrm{pstk}^{+/}$and $13 \mathrm{ps}^{+/-}$ $(0.76 \%)$. The most and least frequent types in females were $\operatorname{inv}(9)(\mathrm{p} 13 \mathrm{q} 21)(32.17 \%)$ and 13ps ${ }^{+/}, 14 \mathrm{ps}^{+/-}, 13 \mathrm{pstk}^{+/-}$, and $14 \mathrm{pstk}^{+/-}(0.87 \%)$, respectively.

As shown in Table 2, the four groups were compared in terms of the age, BMI, infertility duration, baseline FSH level, duration of $\mathrm{Gn}$ stimulation, the total $\mathrm{Gn}$ dose, the $\mathrm{E}_{2}$ concentration on the day of HCG administration, the retrieved oocyte number, progesterone level, and endometrial thickness on the day of HCG administration. Except for the IVF and ICSI percentage, there were no significant differences for any of the parameters $(P>0.05)$.

To determine whether the insemination methods affect the clinical outcomes of chromosomal polymorphisms patients, we studied the embryological and clinical outcomes of chromosomal polymorphism carriers undergoing IVF or ICSI, respectively, as shown in Table 3 and Table 4.

When the analyses were limited to patients undergoing IVF insemination, as shown in Table 3, the results indicated that there were no significant differences in the fertilization rate, $1 \mathrm{PN}$ fertilization rate, $2 \mathrm{PN}$ fertilization rate, multi-PN fertilization rate, good-quality embryo rate, clinical pregnancy rate, or implantation rate $(P>0.05)$. However, the $\mathrm{D} / \mathrm{G}$ group and inv(9) group had lower $2 \mathrm{PN}$ cleavage rates than the control group (92.59\% and $88.58 \%$ vs. $97.66 \%$, respectively) $(P<0.05)$, and the early miscarriage rate in the inv(9) patients was higher than that in the control group $(21.4 \%$ vs. $3.0 \%$, $P<0.05$ ).

Similarly, we further restricted the analysis to the ICSI patients, and the results indicated that there were no significant differences in the fertilization rate, $1 \mathrm{PN}$ fertilization rate, $2 \mathrm{PN}$ fertilization rate, multi-PN fertilization rate, good-quality embryo rate, or implantation rate among the four groups. Surprisingly, the clinical pregnancy rate of the $D / G$ group was significantly higher than that of the control group, and the early miscarriage rate in the inv(9) group, similar to that in the IVF patients, was also significantly higher than that in the control group (Table 4).

To further determine whether the carriers' gender affect the IVF/ICSI outcomes in chromosomal polymorphism patients, we compared the embryological and clinical outcomes of the female and male carriers, as shown in Table 5. The results indicated that the fertilization rate and $2 \mathrm{PN}$ cleavage rate of female carriers in the $\mathrm{D} / \mathrm{G}$ group and inv(9) were significantly lower than those in the control group. Interestingly, the couples with male carriers in these two groups did not show any significant differences. In addition, both the female and male carriers in the inv(9) group had a higher early miscarriage rate than the control group, but there were no significant differences in the other groups (Table 5).

\section{Discussion}

Until now, few reports have paid particular attention to the effects of female chromosomal polymorphisms on infertility, and no previous reports have stratified infertility according to the specific type of chromosomal heteromorphism on outcomes of IVF-embryo transfer. Our study firstly subdivided the chromosomal polymorphism infertility group into three groups (1/9/16 $\mathrm{qh}^{+/-}$group, D/G group, and inv(9) group) to investigate the association between detailed chromosomal polymorphism types and IVF/ICSI outcomes.

\section{$1 / 9 / 16 \mathrm{qh}^{+/-}$}

It is common in chromosome polymorphism variations that the length of the secondary constriction in the long arm of chromosomes 1, 9, and 16 increases and decreases [31]. Both infertile males and females were found to frequently have a $9 \mathrm{qh}^{+}$karyotype. It seems that the increase in highly repetitive DNA sequences in the distal chromosome segments may cause clinical symptoms. However, the structure and function of these duplicate DNA sequences in chromosomes 
Table 1 Frequency and polymorphic variants observed in chromosomal polymorphisms patients

\begin{tabular}{|c|c|c|c|c|c|c|c|}
\hline Classification & Karyotypes & $\begin{array}{l}\text { No. of male } \\
(n=131)\end{array}$ & $\begin{array}{l}\text { Composition ratio } \\
(\%)\end{array}$ & $\begin{array}{l}\text { No. of female } \\
(n=115)\end{array}$ & $\begin{array}{l}\text { Composition ratio } \\
(\%)\end{array}$ & $\begin{array}{l}\text { Total no. } \\
(n=246)\end{array}$ & $\begin{array}{l}\text { Composition ratio } \\
(\%)\end{array}$ \\
\hline \multicolumn{8}{|l|}{$\mathrm{qh}^{+}$} \\
\hline & $1 \mathrm{qh}^{+/-}$ & 42 & 32.06 & 32 & 27.83 & 74 & 30.08 \\
\hline & $9 \mathrm{qh}^{+/-}$ & 14 & 10.69 & 7 & 6.09 & 21 & 8.53 \\
\hline & $16 \mathrm{qh}^{+/-}$ & 19 & 14.50 & 15 & 13.04 & 34 & 13.82 \\
\hline \multicolumn{8}{|c|}{ Chromosome variation in $\mathrm{D} / \mathrm{G}$ genomes } \\
\hline & $13 \mathrm{ps}^{+/-}$ & 1 & 0.76 & 1 & 0.87 & 2 & 0.81 \\
\hline & $14 \mathrm{ps}^{+/-}$ & 2 & 1.53 & 1 & 0.87 & 3 & 1.22 \\
\hline & $15 \mathrm{ps}^{+/-} / \mathrm{pss}$ & 3 & 2.29 & 2 & 1.74 & 5 & 2.03 \\
\hline & $21 \mathrm{ps}^{+/-} / \mathrm{pss}$ & 4 & 3.05 & 5 & 4.34 & 9 & 3.66 \\
\hline & $22 \mathrm{ps}^{+/-}$ & 2 & 1.53 & 3 & 2.61 & 5 & 2.03 \\
\hline & $13 \mathrm{pstk}^{+/-}$ & 3 & 2.29 & 1 & 0.87 & 4 & 1.63 \\
\hline & $14 \mathrm{pstk}^{+/-}$ & 2 & 1.53 & 1 & 0.87 & 3 & 1.22 \\
\hline & $15 \mathrm{pstk}^{+/-}$ & 1 & 0.76 & 4 & 3.48 & 5 & 2.03 \\
\hline & $21 \mathrm{pstk}^{+/-}$ & 6 & 4.58 & 2 & 1.74 & 8 & 3.25 \\
\hline & $22 \mathrm{pstk}^{+/-}$ & 7 & 5.34 & 4 & 3.48 & 11 & 4.29 \\
\hline \multicolumn{8}{|c|}{ Chromosome 9 pericentric inversion } \\
\hline & $\begin{array}{l}\operatorname{inv}(9) \\
\quad(\mathrm{p} 13 \mathrm{q} 21)\end{array}$ & 25 & 19.08 & 37 & 32.17 & 62 & 25.20 \\
\hline
\end{tabular}

Values are number (or percentage)

$q h^{+\digamma}$ increases or decrease in the lengths of the heterochromatic regions on the long arms of chromosomes, $p s^{+/}$increase or decrease in the length of short arm satellites, $p s s$ two short arm satellites, $p s t k^{+}$increase or decrease in the length of short arm stalks, inv(9) inversion 9

1,9 , and 16 remain unknown. In the current study, the results showed that for the $1 / 9 / 16 \mathrm{qh}^{+/-}$group, there were no significant differences on embryological and clinical outcomes compared with those in the control group, regardless

Table 2 Basal characteristics of infertile couples

\begin{tabular}{|c|c|c|c|c|c|}
\hline & Control & $1,9,16 \mathrm{qh}^{+/-}$group & $\mathrm{D} / \mathrm{G}$ group & $\operatorname{inv}(9)$ & $P$ value \\
\hline No. of case & 1088 & 129 & 56 & 62 & \\
\hline Female age (years) & $30.88 \pm 3.23$ & $31.35 \pm 4.43$ & $30.91 \pm 4.03$ & $31.04 \pm 4.56$ & 0.799 \\
\hline BMI of women $\left(\mathrm{kg} / \mathrm{m}^{2}\right)$ & $22.39 \pm 3.16$ & $22.05 \pm 3.61$ & $22.65 \pm 3.50$ & $22.76 \pm 3.56$ & 0.509 \\
\hline Duration of infertility (years) & $4.3 \pm 3.09$ & $5.14 \pm 3.66$ & $4.75 \pm 2.87$ & $4.78 \pm 3.37$ & 0.803 \\
\hline Baseline FSH (IU/L) & $6.68 \pm 1.79$ & $6.63 \pm 2.13$ & $6.52 \pm 1.61$ & $6.73 \pm 1.81$ & 0.159 \\
\hline Male carrier $(\%)$ & - & $74(57.4)$ & $32(57.1)$ & $25(40.3)$ & 0.068 \\
\hline Female carrier $(\%)$ & - & $55(42.6)$ & $24(42.9)$ & $37(59.7)$ & \\
\hline Long protocol $(\%)$ & $914(77.33)$ & $98(75.97)$ & $41(73.21)$ & $46(74.19)$ & 0.838 \\
\hline GnRH antagonist protocol (\%) & $268(22.67)$ & $31(24.03)$ & $15(26.79)$ & $16(25.81)$ & \\
\hline $\operatorname{IVF}(\%)$ & $908(83.5)$ & $90(69.8)$ & $34(60.7)$ & $44(71.0)$ & 0.014 \\
\hline ICSI (\%) & $180(16.5)$ & $39(30.2)$ & $22(39.3)$ & $18(29.0)$ & \\
\hline Duration of Gn (days) & $10.25 \pm 1.82$ & $10.13 \pm 1.65$ & $10.38 \pm 1.64$ & $10.50 \pm 2.69$ & 0.142 \\
\hline Starting Gn dose (IU) & $192.89 \pm 38.98$ & $196.97 \pm 45.21$ & $194.53 \pm 41.89$ & $196.97 \pm 45.22$ & 0.360 \\
\hline Total Gn ampoules(75 IU) & $28.69 \pm 9.98$ & $29.00 \pm 10.76$ & $27.92 \pm 8.89$ & $30.32 \pm 14.22$ & 0.355 \\
\hline $\mathrm{E}_{2}$ level on $\mathrm{HCG}$ day $(\mathrm{pg} / \mathrm{mL})$ & $4286.67 \pm 2202.32$ & $3899.19 \pm 2204.88$ & $4421.89 \pm 2748.18$ & $3988.46 \pm 2417.62$ & 0.139 \\
\hline Thickness of endometrium on HCG day (mm) & $1.05 \pm 0.21$ & $1.03 \pm 0.21$ & $1.09 \pm 0.22$ & $1.06 \pm 0.21$ & 0.206 \\
\hline Progesterone & $1.14 \pm 0.57$ & $1.10 \pm 0.51$ & $1.05 \pm 0.45$ & $1.13 \pm 0.53$ & 0.206 \\
\hline
\end{tabular}

Values are number (or percentage). $P$ value $<0.05$ was considered to be significantly. All continuous variables are expressed as mean $\pm \mathrm{SD}$ $B M I$ body mass index, FSH follicle stimulating hormone, GnRH gonadotropin-releasing hormone, IVF in vitro fertilization, ICSI intracytoplasmic sperm injection, $G n$ gonadotropin, $H C G$ human chorionic gonadotropin, $E_{2}$ estradiol 
Table 3 Comparison of clinical outcomes of IVF-ET cycles among the four groups

\begin{tabular}{lllll}
\hline & Control & $1,9,16 \mathrm{qh}^{+/}$group & $\mathrm{D} / \mathrm{G}$ group & inv(9) \\
\hline No. of case & 908 & 90 & 33 & 44 \\
No. oocytes retrieved & $13.67 \pm 5.87$ & $12.41 \pm 6.93$ & $13.88 \pm 7.83$ & $13.59 \pm 8.39$ \\
1PN fertilization rate (\%) & $3.45 \pm 6.01$ & $4.40 \pm 1.25$ & $2.07 \pm 3.99$ & $1.71 \pm 7.71$ \\
2PN fertilization rate (\%) & $56.39 \pm 19.46$ & $57.19 \pm 23.44$ & $57.41 \pm 23.92$ & $57.49 \pm 27.33$ \\
Multi-PN fertilization rate (\%) & $9.73 \pm 10.75$ & $9.07 \pm 10.78$ & $10.28 \pm 16.01$ & $5.49 \pm 8.09$ \\
Fertilization rate (\%) & $69.58 \pm 19.44$ & $70.44 \pm 21.03$ & $67.59 \pm 25.52$ & $64.70 \pm 26.80$ \\
2PN cleavage rate (\%) & $97.66 \pm 7.15$ & $96.36 \pm 16.07$ & $92.59 \pm 23.84^{\mathrm{a}}$ & $88.58 \pm 29.17^{\mathrm{a}}$ \\
Quality embryo rate (\%) & $54.48 \pm 24.92$ & $53.04 \pm 27.99$ & $53.74 \pm 26.23$ & $55.69 \pm 32.93$ \\
Implantation rate (\%) & $32.4(394 / 1215)$ & $30.4(38 / 125)$ & $30.8(12 / 39)$ & $37.5(18 / 48)$ \\
Clinical pregnancy rate (\%) & $47.3(298 / 630)$ & $47.0(31 / 66)$ & $45(9 / 20)$ & $58.3(14 / 24)$ \\
Early miscarriage rate (\%) & $3.0(9 / 298)$ & $3.2(1 / 31)^{*}$ & $0(0 / 9)$ & $21.4(3 / 14)^{\mathrm{b} *}$ \\
\hline
\end{tabular}

${ }^{\text {a }} P<0.05$, difference between chromosomal polymorphisms group and the control group

${ }^{\mathrm{b}} P<0.01$, difference between chromosomal polymorphisms group and the control group

$P N$ pronuclei

*Fisher's exact test

All continuous variables are expressed as mean $\pm \mathrm{SD}$ of whether IVF or ICSI was utilized. Also, there is no significant difference in embryological and clinical outcomes between different gender carriers. It appears that $1 / 9 / 16 \mathrm{qh}^{+/-}$has no apparent adverse effect on the clinical outcomes, neither males nor females, ICSI or IVF, which is consistent with the current study.

\section{Variations in chromosome 9}

The inversion of chromosome 9 heterochromatin is an observable structural difference between human karyotypes and chimpanzee karyotypes [32]. The mechanisms of the origin of inv(9) are highly complex [33]. Recently, the DNA sequencing and analysis of human chromosome 9 showed that it contains the largest autosomal block of heterochromatin and is highly structurally polymorphic and heteromorphic in 6-8\% of humans. Several authors have suggested possible associations between the inv(9) and specific clinical observations, such as diagnosis of schizophrenia [34, 35], an increased risk of offspring with Down syndrome [8], and particularly, the occurrence of higher incidence of intrauterine fetal death [36]. However, the mechanism of the inv(9)'s effects on fertility has not been fully characterized.
Table 4 Comparison of the outcomes of ICSI-ET cycles among the four groups

\begin{tabular}{lllll}
\hline & Control & $1,9,16 \mathrm{qh}^{+/}$group & $\mathrm{D} / \mathrm{G}$ group & inv(9) \\
\hline No. of case & 180 & 39 & 22 & 18 \\
No. oocytes retrieved & $12.93 \pm 5.61$ & $14.31 \pm 6.69$ & $15.91 \pm 6.54$ & $13.56 \pm 8.34$ \\
1PN fertilization rate & $2.49 \pm 4.82$ & $3.37 \pm 6.81$ & $1.76 \pm 3.72$ & $5.53 \pm 6.32$ \\
2PN fertilization rate & $54.03 \pm 20.84$ & $55.45 \pm 19.63$ & $53.93 \pm 20.07$ & $56.13 \pm 23.97$ \\
Multi-PN fertilization rate & $1.87 \pm 4.84$ & $1.92 \pm 3.64$ & $1.45 \pm 3.44$ & $1.34 \pm 3.63$ \\
Fertilization rate (\%) & $59.07 \pm 19.02$ & $60.74 \pm 19.53$ & $57.13 \pm 19.24$ & $63.00 \pm 22.82$ \\
2PN cleavage rate (\%) & $97.16 \pm 11.52$ & $95.11 \pm 17.93$ & $98.46 \pm 4.24$ & $93.03 \pm 23.45$ \\
Quality embryo rate (\%) & $52.33 \pm 28.15$ & $57.18 \pm 32.22$ & $59.27 \pm 18.34$ & $50.46 \pm 28.69$ \\
Implantation rate (\%) & $23.69(59 / 190)$ & $28.6(16 / 56)$ & $44.8(13 / 29)^{\mathrm{a}}$ & $30.8(8 / 26)$ \\
Clinical pregnancy rate (\%) & $40.65(50 / 123)$ & $37.9(11 / 29)$ & $78.6(11 / 14)^{\mathrm{a}}$ & $61.5(8 / 13)$ \\
Early miscarriage rate (\%) & $2(1 / 50)^{*}$ & $9.1(1 / 11)^{*}$ & $0(0 / 11)$ & $50(4 / 8)^{\mathrm{b} *}$ \\
\hline
\end{tabular}

${ }^{\text {a }} P$ value $<0.05$, difference between chromosomal polymorphisms group and control group

${ }^{\mathrm{b}} P$ value $<0.01$, difference between chromosomal polymorphisms group and control group

$P N$ pronuclei

*Fisher's exact test

All continuous variables are expressed as mean $\pm \mathrm{SD}$ 
Table 5 Comparison of the IVF/ICSI outcomes among the four groups

\begin{tabular}{|c|c|c|c|c|c|c|c|}
\hline & \multirow[t]{2}{*}{ Control } & \multicolumn{2}{|c|}{$1,9,16 \mathrm{qh}^{+/-}$group } & \multicolumn{2}{|l|}{$\mathrm{D} / \mathrm{G}$ group } & \multicolumn{2}{|l|}{ inv(9) group } \\
\hline & & Female & Male & Female & Male & Female & Male \\
\hline No. of case & 1088 & 54 & 75 & 24 & 31 & 37 & 25 \\
\hline No. oocytes retrieved & $13.55 \pm 5.83$ & $12.27 \pm 6.77$ & $13.51 \pm 6.98$ & $15.08 \pm 7.92$ & $14.37 \pm 7.01$ & $13.73 \pm 7.65$ & $13.36 \pm 9.36$ \\
\hline $1 \mathrm{PN}$ fertilization rate $(\%)$ & $3.29 \pm 5.84$ & $3.53 \pm 6.28$ & $4.50 \pm 13.70$ & $2.04 \pm 3.71$ & $1.88 \pm 4.03$ & $4.35 \pm 9.30$ & $0.56 \pm 1.94^{\mathrm{ab}}$ \\
\hline 2PN fertilization rate $(\%)$ & $56.00 \pm 19.71$ & $57.09 \pm 21.28$ & $56.34 \pm 23.16$ & $49.72 \pm 24.8^{\mathrm{b}}$ & $60.7 \pm 19.38$ & $53.51 \pm 28.19$ & $62.39 \pm 22.47$ \\
\hline Multi-PN fertilization rate (\%) & $8.43 \pm 10.04$ & $7.07 \pm 11.27$ & $6.79 \pm 8.59$ & $3.25 \pm 10.31^{\mathrm{ab}}$ & $9.49 \pm 14.78$ & $3.51 \pm 6.60^{\mathrm{a}}$ & $5.45 \pm 8.24$ \\
\hline Fertilization rate $(\%)$ & $67.73 \pm 20.08$ & $67.34 \pm 20.74$ & $67.63 \pm 21.32$ & $55.01 \pm 27.43^{\mathrm{ab}}$ & $69.84 \pm 18.32$ & $61.37 \pm 27.89^{\mathrm{a}}$ & $68.40 \pm 21.42$ \\
\hline 2PN cleavage rate $(\%)$ & $97.58 \pm 8.03$ & $96.54 \pm 15.15$ & $95.57 \pm 17.68$ & $90.67 \pm 28.16^{\mathrm{ab}}$ & $98.06 \pm 4.42$ & $86.44 \pm 31.40^{\mathrm{ab}}$ & $94.95 \pm 19.99$ \\
\hline Quality embryo rate (\%) & $54.02 \pm 25.63$ & $53.05 \pm 29.745$ & $55.22 \pm 29.09$ & $55.68 \pm 23.66$ & $56.09 \pm 23.63$ & $54.88 \pm 34.46$ & $53.13 \pm 22.52$ \\
\hline Implantation rate $(\%)$ & $32.24(453 / 1405)$ & $33.75(27 / 80)$ & $26.73(27 / 101)$ & $34.38(11 / 32)$ & $38.89(14 / 36)$ & $31.91(15 / 47)$ & $40.74(11 / 27)$ \\
\hline Clinical pregnancy rate $(\%)$ & $46.22(348 / 753)$ & $53.66(22 / 41)$ & $37.04(20 / 54)$ & $56.25(9 / 16)$ & $61.11(11 / 18)$ & $56.52(13 / 23)$ & $64.29(9 / 14)$ \\
\hline Early miscarriage rate (\%) & $2.87(10 / 348)$ & 0 & $10(2 / 20)^{*}$ & 0 & 0 & $23.08(3 / 13)^{a *}$ & $44.44(4 / 9)^{*}$ \\
\hline
\end{tabular}

${ }^{\text {a }} P$ value $<0.05$, difference between chromosomal polymorphisms group and control group

${ }^{\mathrm{b}} P$ value $<0.05$, difference between female carriers and male carriers

$P N$ pronuclei

*Fisher's exact test

All continuous variables are expressed as mean $\pm \mathrm{SD}$

In the present study, we found that inv(9) patients had a lower 2PN cleavage rate than that in the control patients when utilized IVF insemination but had no significantly difference when utilized ICSI. In addition, they had a higher early miscarriage rate both in the ICSI and IVF groups. We explored the role of gender on IVF/ICSI outcomes, and the results indicated that the 2PN cleavage rate of female inv(9) carriers was significantly lower than that in the control or male carrying patients. The role of inv(9) in human infertility remains unclear. Some authors have proposed that during meiosis, the inversion itself can interfere with the pairing of homologous chromosomes; this mechanism of recombination aneusomy is well described for some types of pericentric inversions [37]. $\operatorname{Inv}(9)$ has also been suggested to have some interchromosomal effects that lead to a higher incidence of mitotic disturbances, which is likely associated with aneuploidies, such as trisomy 21 [38]. This observation is in agreement with our findings that the cleavage rate of inv(9) patients is lower than that in the control patients. Śípek et al. compared inv(9) carriers and control subjects for each sex separately and found a statistically significantly higher incidence of heterochromatin variants (including the group of variants on chromosome 9) in females, but not in males, with idiopathic reproductive failure [39]. This partially supported our findings that inv(9) in females leads to a lower cleavage rate and higher early miscarriage rate. Conversely, the study of Liang et al. indicated that the female carrier group had a higher normal fertilization rate and higher utilization rate than the male carrier group, which showed a tendency of better prognosis for the female carrier group [40]. This controversial results needs to be confirmed by a larger study. The possible gender-dependent differences in the potential meiotic mechanisms remain to be clarified.

Another finding of our study was that inv(9) leads to an increasing rate of early miscarriage Recently, Merrion et al. investigated the unbalanced chromosome rearrangement rate from inv(9) patients who underwent IVF with preimplantation genetic testing for structural rearrangements (PGT-SR) and found that the chromosome 9 pericentric inversions did not result in unbalanced structural rearrangements in day $5 / 6 \mathrm{em}-$ bryo samples [41]. It was also reported that some genes located in 9p13, such as Talin1 and MELK, might be related to early embryo implantation potential and/or endometrial receptivity [42], which help us inferring that we should consider the possibility of implantation potential and endometrial receptivity impacts of inv(9). Also, it could be due to the potential capability of eggs in repairing sperm-derived defects but not vice versa. The role of inv(9) in human infertility remains unclear, and the clinical importance of any individual inv(9) in a specific clinical pathology may be challenging to determine.

\section{D/G}

$\mathrm{D} / \mathrm{G}$ chromosomes are common chromosome heteromorphisms that show increased heterochromatin at the chromosome telomere, with short variants at the NORs. For the human acro chromosomes, the metaphase NORs contain ribosomal genes, and these genes are clustered on the short arm 
stalks, exhibiting polymorphic variations. For D/G chromosomes, the heterochromatin located in centromeres plays an important role in spindle attachment, chromosome movement, meiotic pairing, and sister chromatid cohesion [43]. To date, no study has reported the relationship between $\mathrm{D} / \mathrm{G}$ group chromosomal variations and reproductive outcomes.

Our study first revealed that the 2PN cleavage rate of D/G polymorphism carriers was significantly lower than that in the control patients undergoing IVF treatments, but not ICSI. Surprisingly, in the ICSI group, the clinical pregnancy rate and implantation rate of the $\mathrm{D} / \mathrm{G}$ patients were significantly higher than those in the control patients. Furthermore, the fertilization rate and 2PN cleavage rate of the female carriers were significantly lower than those of the control and male carrying patients, but no significant difference was found for male carriers. These results indicate that $\mathrm{D} / \mathrm{G}$ chromosome polymorphisms in females lead to a lower fertilization rate and cleavage rate but these polymorphisms in male carriers seem to have no adverse effects on reproductive outcomes. Chromatin variations in $\mathrm{D} / \mathrm{G}$ regions can cause defects in kinetochore assembly and centromere function, cause difficulty in homologous chromosome pairing, have impacts on cell division, and finally affect gamete formation. This also was supported by our research results that female carriers in the $\mathrm{D} /$ $\mathrm{G}$ group have lower fertilization and cleavage rates.

Increasing evidence has confirmed that female reproductive disorders are closely associated with chromosomal polymorphisms [29]. However, Madon et al. [3] reported that male partners displayed chromosomal polymorphism variations that had no adverse effects on pregnancy rates, suggesting that chromosomal heteromorphism in infertile males may have no adverse effect on IVF/ICSI treatment, which is consistent with our findings. Besides, the clinical pregnancy rate and implantation rate of the $D / G$ group were significantly higher than those of the control group in ICSI patients, while there is no significant difference in patients with IVF insemination, which indicates that ICSI insemination might be a better choice for $\mathrm{D} / \mathrm{G}$ chromosomal polymorphism patients. Also, considering the limited sample size of the ICSI patients, further study is needed to confirm.

Based on our results, we conclude that the inv(9) and D/G groups of chromosomal polymorphisms play essential roles in female infertility, leading to a lower cleavage rate and inv(9) adversely increasing the early miscarriage rate after IVF treatment. For D/G groups, ICSI insemination may benefit patients who have a chance of clinical pregnancy. $1 / 9 / 16 \mathrm{qh}^{+/-}$has no apparent adverse effect on the clinical outcomes. We should provide individual genetic counseling suggestions according to the polymorphism type.

One limitation of our study is that the number of heteromorphism carriers undergoing ICSI is insufficient. For more statistical power, further studies with larger sample sizes are needed. Another limitation is that our study did not eliminate the potential effects of polymorphism variations on male sperm formation. Furthermore, the chromosome analysis method in the present study had a banding resolution of 400-550 BPHS, which may have caused some potential variations that could not be distinguished from common polymorphism variations.

Author contributions SJL, YXC, and JY conceived and designed the study. YS, YZ, and DNZ collected the data. TLY performed the statistical analyses. SJL and YXC drafted and revised the manuscript. All authors read and approved the final manuscript.

Funding information This work was supported by grants from the National Natural Science Foundation of China (no. 81701412), the Natural Science Foundation of Hubei Province Grant (no. 2018CFB491), the China Scholarship Council (no. 201806275007), the Hubei Chenguang Talented Youth Development Foundation (Class B project in 2018), and the Merck Serono China Research Fund for Fertility Experts (no. MerckSerono_CREATE-2016141).

\section{Compliance with ethical standards}

Conflict of interest The authors declare that they have no conflict of interest.

Open Access This article is licensed under a Creative Commons Attribution 4.0 International License, which permits use, sharing, adaptation, distribution and reproduction in any medium or format, as long as you give appropriate credit to the original author(s) and the source, provide a link to the Creative Commons licence, and indicate if changes were made. The images or other third party material in this article are included in the article's Creative Commons licence, unless indicated otherwise in a credit line to the material. If material is not included in the article's Creative Commons licence and your intended use is not permitted by statutory regulation or exceeds the permitted use, you will need to obtain permission directly from the copyright holder. To view a copy of this licence, visit http://creativecommons.org/licenses/by/4.0/.

\section{References}

1. Bhasin MK. Human population cytogenetics: a review. Int J Hum Genet. 2005;5:83-152.

2. Hong Y, Zhou YW, Tao J, Wang SX, Zhao XM. Do polymorphic variants of chromosomes affect the outcome of in vitro fertilization and embryo transfer treatment? Hum Reprod. 2011;26:933-40.

3. Madon PF, Anthalye AS, Parikh FR. Polymorphic variants on chromosomes probably play a significant role in infertility. Reprod BioMed Online. 2005;11:726-32.

4. Mitelman F. ISCN 1995: an international system for human cytogenetic nomenclature. Karger, Basel, pp 1995;44-45.

5. Borgaonkar DS. Chromosomal variation in man:a catalogue of chromosomal variants and anomalies. New York: Wiley-Liss; 1997.

6. Boué J, Taillemite JL, Hazael-Massieux P, Léonard C, Boué A. Association of pericentric inversion of chromosome 9 and reproductive failure in ten unrelated families. Hum Gene Ther. 1975;30: 217-24.

7. Metaxotou C, Kalpini-Mavrou A, Panagou M, Tsenghi C. Polymorphism of chromosome 9 in 600 Greek subjects. Am J Hum Genet. 1978;30:85-9. 
8. Serra A, Brahe C, Millington-Ward A, Neri G, Tedeschi B, Tassone F, et al. Pericentric inversion of chromosome 9: prevalence in 300 Down syndrome families and molecular studies of nondisjunction. Am J Med Genet Suppl. 1990;7:162-8.

9. Demirhan O, Pazarbasi A, Suleymanova-Karahan D, Tanriverdi N, Kilinc Y. Correlation of clinical phenotype with a pericentric inversion of chromosome 9 and genetic counseling. Saudi Med J. 2008;29:946-51.

10. Šipek A Jr, Panczak A, Mihalova R, Suttrova E, Sobotka V. Pericentric inversion of human chromosome 9 epidemiology study in Czech males and females. Folia Biol (Praha). 2015;61:140-6.

11. Ran C, Ma Y, Ying N, et al. Chromosomal polymorphisms are associated with female infertility and adverse reproductive outcomes after infertility treatment: a 7-year retrospective study. Reprod BioMed Online. 2017;72.

12. Schaffer LG, McGowan-Jordan J, Schmid M. ISCN 2013: an international system for human cytogenetic nomenclature. Basel: Karger Publishers; 2012.

13. Evans H, Gosden J, Mitchell A, et al. Location of human satellite DNAs on the Y chromosome. Nature. 1974b;251:346-7.

14. Rooney D. Human cytogenetics: constitutional analysis. Oxford: Oxford University Press; 2001. p. 12-5.

15. Sasagawa I, Ishigooka M, Kubota Y, Tomaru M, Hashimoto T, Nakada T. Pericentric inversion of chromosome 9 in infertile men. Int Urol Nephrol. 1998;30:203-7.

16. Lissitsina J, Mikelsaar R, Varb K, et al. Cytogenetic study in infertile men. Ann Genet. 2003;46:185.

17. Parikh F, Madon P, Athalye A, et al. Analysis of male factor infertility. Int J Hum Genet. 2004;Supplement.no. 1:13.

18. Madon P, Athalye A, Parikh F. High incidence of chromosome polymorphic variants in infertile couples. ISAR 2005 Programme and Abstract Book, India. 2005.

19. Patel Z, Madon $\mathrm{P}$, Adhia $\mathrm{R}$ et al. Chromosomal rearrangements in couples with recurrent pregnancy losses-874 cases. Abstract book of VIII International Conf. on Early Prenatal Diagnosis and Therapy. Goa, India.1996.

20. Thomas IM. Cytogenetic basis of recurrent abortions. Perinatology. 1999;1:181-7.

21. Yuce H, Tekedereli I, Elyas H. Cytogenetic results of recurrent spontaneous miscarriages in Turkey. Med Sci Monit. 2007;13: CR286-9.

22. Sahin FI, Yilmaz Z, Yuregir OO, Bulakbasi T, Ozer O, Zeyneloglu HB. Chromosome heteromorphisms: an impact on infertility. J Assist Reprod Genet. 2008;25:191-5.

23. Di Gennaro G, Mascia A, Grammaldo L. Focal cortical dysplasia and pericentric inversion of chromosome 9: a case report. J Neurol Sci [Turkish]. 2004;21:143-6.

24. Silber SJ, Alagappan R, Brown LG, Page DC. Y chromosome deletions in azoospermic and severely oligozoospermic men undergoing intracytoplasmic sperm injection after testicular sperm extraction. Hum Reprod. 1998;13:3332-7.

25. van Golde RJ, Wetzels AM, de Graaf R, Tuerlings JH, Braat DD, Kremer JA. Decreased fertilization rate and embryo quality after ICSI in oligozoospermic men with microdeletions in the azoospermia factor c region of the Y chromosome. Hum Reprod. 2001;16: 289-92.

26. Oates RD, Silber S, Brown LG, Page DC. Clinical characterization of 42 oligospermic or azoospermic men with microdeletion of the AZFc region of the $\mathrm{Y}$ chromosome, and of 18 children conceived via ICSI. Hum Reprod. 2002;17:2813-24.
27. Choi JM, Chung P, Veeck L, Mielnik A, Palermo GD, Schlegel PN. AZF microdeletions of the $\mathrm{Y}$ chromosome and in vitro fertilization outcome. Fertil Steril. 2004;81:337-41.

28. Guo T, Qin Y, Gao X, Chen H, Li G, Ma J, et al. The role of male chromosomal polymorphism played in spermatogenesis and the outcome of IVF/ICSI-ET treatment. Int J Androl. 2012;35:802-9.

29. Caglayan AO, Ozyazgan I, Demiryilmaz F, Dundar M. Cytogenetic results of patients with infertility in Middle Anatolia, Turkey: do heterochromatin polymorphisms affect fertility? J Reprod Infertil. 2010a; $11: 179-81$.

30. Mierla D, Stoian V. Chromosomal polymorphisms involved in reproductive failure in the Romanian population. Balkan J Med Genet. 2012b;15:23-8.

31. Minocherhomji S, Athalye AS, Madon PF, Kulkarni D, Uttamchandani SA, Parikh FR. A case-control study identifying chromosomal polymorphic variations as forms of epigenetic alterations associated with the infertility phenotype. Fertil Steril. 2009;92:88-95.

32. Kehrer-Sawatzki H, Szamalek JM, Tänzer S, Platzer M, Hameister $\mathrm{H}$. Molecular characterization of the pericentric inversion of chimpanzee chromosome 11 homologous to human chromosome 9. Genomics. 2005;5:542-50.

33. Verma RS. A reply: pericentric inversion of chromosome 9qh are 'real' but the mechanisms of their origin are highly complex. Hum Genet. 1999; 105:183-4.

34. Lee KB, Kunugi H, Nanko S. Familial schizophrenia with pericentric inversion of chromosome 9: a case report. Schizophr Res. 1998;32:123-6.

35. Kunugi H, Lee KB, Nanko S. Cytogenetic findings in 250 schizophrenics: evidence confirming an excess of the $\mathrm{X}$ chromosome aneuploidies and pericentric inversion of chromosome 9. Schizophr Res. 1999;40:43-7.

36. Uehara S, Akai Y, Takeyama Y, Takabayashi T, Okamura K, Yajima A. Pericentric inversion of chromosome 9 in prenatal diagnosis and infertility. Tohoku J Exp Med. 1992;166:417-27.

37. Anton E, Blanco J, Egozcue J, Vidal F. Sperm studies in heterozygote inversion carriers: a review. Cytogenet Genome Res. 2005;111:297-304.

38. Murthy S, Prabhakara K. Mitotic disturbances associated with inversion 9qh. A case report. Ann Genet. 1990;33:243-4.

39. Š́pek A Jr, Mihalová R, Panczak A, Hrčková L, Janashia M, Kaspř́íková N, et al. Heterochromatin variants in human karyotype: a possible association with reproductive failure. Reprod BioMed Online. 2014;29:245-50.

40. Liang S, Yang J, Wu H, Teng X, Duan T. Effects of chromosome 9 inversion on IVF/ICSI: a 7-year retrospective cohort study. Molec Genet Genom Med. 2019:7(9).

41. Merrion K, Maisenbacher M. Pericentric inversion (Inv) 9 variant-reproductive risk factor or benign finding? J Assist Reprod Genet. 2019;36(12):2557-61.

42. Lerer I, Sagi M, Meiner V, Cohen T, Zlotogora J, Abeliovich D. Deletion of the ANKRD15 gene at 9p24.3 causes parent-of-origindependent inheritance of familial cerebral palsy. Hum Mol Genet. 2005;14(24):3911-20.

43. Karpen G, Endow S. Meiosis: chromosome behaviour and spindle dynamics. In: Endow S, Glover D, editors. Frontiers in biology. Oxford: Oxford University Press; 1998.

Publisher's note Springer Nature remains neutral with regard to jurisdictional claims in published maps and institutional affiliations. 